\title{
A história social anglo-americana desde 1945*
}

\author{
Charles Tilly \\ Tradução de Otaćlilo Nunes
}

A história social examina mudanças em instituições e estruturas relevantes ou consequências dessas mudanças. Ela pesquisa famílias, sistemas de parentesco, comunidades, religiōes, mercados, firmas, indústrias, populações, governos e muito mais. Alguns historiadores sociais concentram-se em reconstruir experiências do viver em tempos e lugares específicos, por exemplo na Constantinopla imperial, na Florença do Renascimento, na Berlim nazista ou no Oeste americano durante o século XIX. Outros delineiam padrões sociais amplos, tais como fluxos de migração e distribuições geográficas das cidades. Mas a maior parte da história social lida com macromudanças na vida social e suas consequências para indivíduos, famílias ou relações interpessoais de pequena escala. Ela vivifica a mudança social.

Em geral, a história social difere dos campos parcialmente sobrepostos da história intelectual e da história cultural por atribuir considerável eficácia causal a estruturas, processos e mudanças sociais. Difere da história política, na média, por sua insistência em embutir a política nos contextos sociais. Difere do campo da história econômica, a ela estreitamente ligado, por examinar interações de duas vias entre processos econômicos e experiências sociais. Sua missão centra-se nos engajamentos individuais e coletivos na mudança social. Tal missão inclina os historiadores sociais à oscilação e à luta perpétuas entre diferentes variedades de idealismo e realismo. $\mathrm{Na}$ perspectiva francesa de Descimon:
* Capítulo 14 de Explaining social processes, de Charles Tilly (Paradigm Publisher, 2009). Agradecemos a Dean Birkenkamp, da Paradigm Publisher, e a Chris Tilly, pela família Tilly, a autorização para republicar este texto. 
O chamado retorno aos eventos se reduz com frequência a uma reação contra a História Total de Fernand Braudel. Ele encoraja duas estratégias explicativas diferentes: um modelo reduzido de ação humana racional em termos de custos e benefícios esperados ou a criatividade sem regras da "história virtual" [...]. Enfrentamos assim um dilema, uma escolha entre reducionismo baseado em raciocínio econômico e interpretação pós-moderna que leva ao reconhecimento de impotência intelectual. Só a análise empírica (os eventos realmente importam!) fornecerá uma saída do impasse ao qual a falsa oposição entre história social e história dos eventos nos levou (Descimon, 1999, p. 319).

Descimon está descrevendo a versão mais atualizada de um dilema muito antigo para historiadores sociais. A história social anglo-americana depois de 1945 expõe com abundância a oscilação e a luta intelectual entre os dois pontos de vista.

Como a história social na França e em outros lugares, a história social profissional nas Ilhas Britânicas e na América do Norte começou com um esforço triplo:

- Reduzir a fixação dos historiadores gerais em líderes, eventos e instituições políticos vistos das alturas do poder.

- Investigar as bases sociais e econômicas da política pública.

- Tomar as pessoas comuns e a vida social rotineira como objetos de estudo social sério.

Essas características marcaram a agenda da história social anglo-americana desde o início do século xx.

Tomada como o estudo histórico da mudança social, a história social anglo-americana contribuiu para a história em geral de várias maneiras. Elevou o estudo da comunidade local de pequena pesquisa antiquária a modo importante de investigação histórica. Deslocou processos sociais, como migração, crescimento populacional, industrialização e urbanização, da condição de influências invocadas vagamente antes de empreender as histórias de elites, ideias e políticas nacionais para a condição de objetos de investigação histórica detalhada e causas potenciais de eventos nacionais. Incorporou procedimentos e achados das ciências sociais ao corpo de práticas, evidências e argumentos históricos. Acostumou a maioria dos historiadores gerais das Ilhas Britânicas e da América do Norte a especificar e diferenciar os termos ao usar abstraçôes como "o povo", "massas" ou 
mesmo "trabalhadores". Fez as relações variáveis entre detentores de poder e diferentes categorias de pessoas comuns terem importância para explicações de mudança histórica.

Depois de 1945, três inovaçôes interconectadas na prática histórica - história dos vencidos, exame exaustivo de registros organizacionais e biografia coletiva - promoveram a influência da história social sobre a história em geral. A expressão "história from the bottom up" parece ter se originado com Frederick Jackson Turner, historiador da fronteira americana (cf. Novick, 1988, p. 442). Os historiadores britânicos no mais das vezes chamavam a mesma abordagem de "história a partir de baixo" [history from below]. Ambas as expressões transmitem uma atitude: a insistência em que pessoas com relativamente pouco poder têm pontos de vista próprios, que esses pontos de vista merecem atenção histórica, que coletivamente e de modo incremental pessoas comuns fazem história. História a partir de baixo também designa a prática de reunir evidências sobre como pessoas comuns de fato viveram grandes mudanças e conflitos sociais. Historiadores de esquerda como J. L. e Barbara Hammond (por exemplo, Hammond e Hammond, 1917), por certo, haviam se concentrado na experiência de pessoas comuns muito antes da Segunda Guerra Mundial. Depois de 1945, essa tornou-se uma das grandes preocupaçôes de toda a história social.

\section{A evidência e seus usos}

Os historiadores sociais do popular enfrentavam, porém, um problema. Diferentemente das pessoas ricas, poderosas e intelectualmente proeminentes, seus objetos de estudo deixaram poucas cartas, diários, autobiografias ou declaraçóes públicas. Como os historiadores poderiam reconstruir as experiências dessas pessoas? O esquadrinhamento de registros organizacionais forneceu grande parte das evidências. Antiquários, historiadores locais e genealogistas por muito tempo haviam buscado nos recessos e nas fendas dos registros organizacionais vestígios de pessoas que não deixavam nenhuma narrativa de sua vida. Registros de nascimentos, mortes e casamentos; arquivos de cartórios; petiçôes; transcrições de julgamentos; listas de empregados; questionários de censo; relatórios policiais; livros de matrícula escolares; e resíduos organizacionais similares registram a passagem de pessoas comuns por diferentes fases de sua vida. Depois da Segunda Guerra Mundial, historiadores sociais anglo-americanos juntaram-se a seus semelhantes em todos os lugares no esquadrinhamento desses registros, em 
busca de informações sobre como pessoas esquecidas vivenciaram migração, industrialização, urbanização e outras mudanças sociais de grande alcance.

A biografia coletiva tornou essas investigaçóes viáveis para mais que um punhado de pessoas. Ela consiste em reunir informações uniformes sobre múltiplas unidades sociais - indivíduos, domicílios, bairros, empresas, associações, e assim por diante - para agregação e comparação. Torna-se um procedimento poderoso quando os investigadores combinam observações de diferentes fontes relativas às mesmas unidades sociais, por exemplo, seguindo indivíduos de um censo ao seguinte ou de folhas de pagamento de firmas a registros de casamento. Esse movimento de uma fonte a outra (normalmente chamado de encadeamento nominal de registros [nominal record linkage]) aumenta histórias de vida parciais ou descrições de grupo a despeito da escassez de informaçôes individuais em algum documento específico.

A biografia coletiva estende-se facilmente de indivíduos a organizações, localidades e eventos. $\mathrm{Na}$ história social anglo-americana, dois tipos de evento - os do ciclo vital e os de confrontação - atraíram o maior esforço. Falando em termos estritos, eventos do ciclo vital incluem nascimentos, doenças e mortes. Por extensão, também abrangem mudanças de localização social como casamento, divórcio, migração e perda de emprego. Registros de eventos do ciclo vital muitas vezes incluem descrições sociais das partes bem como de testemunhas, o que significa que fornecem informações sobre vínculos sociais. É claro que se podem reunir relatos desses eventos para formar histórias de vida de indivíduos, famílias ou domicílios. Mas também é possível examiná-las como agregados, por exemplo, calculando flutuações nas taxas de natalidade e depois relacionando essas flutuaçōes a variações em outros eventos do ciclo vital ou a alteraçôes em condições não demográficas (cf. Charles Tilly, 1978; Willigan e Lynch, 1982).

Similarmente, incidentes de política confrontacional prestam-se à biografia coletiva, (a) seja reunidos como o equivalente de histórias de vida de localidades, grupos ou questóes específicos, (b) seja abstraídos para análise de seus padrōes gerais (cf. Olzak, 1989; Rucht, Koopmans e Neidhardt, 1998). Os governos britânico e norte-americano, por exemplo, começaram a produzir catálogos oficiais de greves e locautes por volta de 1900; com esforço, esses catálogos convertem-se em biografias coletivas de atividade grevista em qualquer uma dessas modalidades. Outros eventos confrontacionais como manifestações públicas, confrontos violentos, manifestações de protesto e linchamentos, geralmente exigem uma compilação de séries 
uniformes extraídas, pelo próprio investigador, de jornais, relatórios policiais, correspondência administrativa e fontes semelhantes. Os historiadores sociais fizeram uma parte de seus trabalhos mais ambiciosos sobre conflitos empregando essas formas de biografia coletiva.

Depois de 1945, inovações técnicas impulsionadas pela guerra foram muito úteis à história social. A reprodução fotográfica barata de fontes e a crescente disponibilidade de computadores eletrônicos facilitaram grandemente o esquadrinhamento de registros organizacionais e a adoção da biografia coletiva como procedimentos importantes dos historiadores sociais. Incentivos sociais redobraram a atratividade dessas inovações técnicas. A grande expansão da educação superior no pós-guerra nas Ilhas Britânicas e, em especial, na América do Norte tanto aumentou o número de historiadores quanto alargou as origens de classe dos historiadores profissionais. Muitos historiadores recém-formados adotaram as inovaçôes técnicas para estudar como grandes mudanças sociais envolveram pessoas que não pertenciam às classes dominantes - com frequência pessoas semelhantes a seus próprios antepassados.

A despeito de enormes variações na terminologia e na ênfase, a maioria dos historiadores sociais anglo-americanos que lidam com o período que começa em 1500 entendeu por muito tempo que as mudanças relevantes formavam dois grandes agrupamentos que interagiam entre si: o desenvolvimento do capitalismo industrial e a criação de governos nacionais poderosos. Assim, os historiadores sociais da família perguntaram repetidamente como a industrialização interagia com mudanças na estrutura dos domicílios e como as relações das autoridades com as famílias pobres alteraram-se com o desenvolvimento de burocracias centrais e Estados do bem-estar. Estudiosos de política local dedicavam-se às vezes às mesmas questóes, mas com maior frequência perguntavam em que grau e como a expansão do trabalho assalariado e o declínio do poder dos patronos locais transformavam as lutas políticas das pessoas comuns.

Dado que diferentes partes das Ilhas Britânicas e da América do Norte experimentaram o desenvolvimento do capitalismo industrial e a criação de governos nacionais poderosos de modos contrastantes e com cronogramas distintos, tanto o peso relativo quanto o tratamento preciso dessas mudanças variam de um período e de um lugar a outro. Vários grupos nacionais de historiadores entre os anglo-americanos - notadamente canadenses, estadunidenses, britânicos e irlandeses - adotaram portanto agendas um pouco diferentes, conforme a situação de seus próprios países. Os acadêmicos 
norte-americanos preocupavam-se muito com imigração e industrialização, os historiadores britânicos, com o passado e o presente do Estado do bem-estar social. Os canadenses despenderam mais esforço que seus vizinhos no estudo das grandes divisões culturais, e acabaram por produzir historiografias separadas em francês e inglês. Temas como atraso, opressão, libertação e emigração aparecem com muito mais força na historiografia irlandesa do que na inglesa. Só uma minoria de historiadores sociais anglo-americanos estudou outras regiōes que não as Ilhas Britânicas e a América do Norte, enquanto um pequeno número de outsiders especializou-se em história social anglo-americana. Membros de ambos os grupos frequentemente viram-se mediando ou alternando entre agendas prevalecentes na origem e no destino.

Algumas preocupações comuns promoveram, não obstante, uma convergência entre historiadores sociais anglo-americanos. No fim da Segunda Guerra Mundial, estudiosos da história social nas Ilhas Britânicas e na América do Norte enfrentaram situações políticas amplamente similares. Seus países haviam emergido relativamente intactos de uma grande guerra. A Depressão e a própria guerra tinham expandido muito a presença do Estado na vida social e fortalecido a posição dele como garantidor ou provedor de direitos sociais. Com seus compatriotas, os historiadores sociais haviam testemunhado a ascensão e a morte de vigorosos regimes fascistas. Um poderoso bloco soviético formara-se em torno de sistemas políticos bastante diferentes daqueles dos anglo-americanos, no momento em que teve início a Guerra Fria. Essas circunstâncias introduziram na agenda geral dos historiadores questôes sobre as origens e os impactos do autoritarismo, do socialismo e da democracia, sobre as bases da ação de massa, sobre a cidadania e a viabilidade de programas de libertação humana concorrentes. A história prometia identificar elos entre passado, presente e futuro em todos esses aspectos.

\section{Marxismo, modernização e outras teorias}

Influenciada pela agenda da história geral, a maioria dos historiadores sociais anglo-americanos do período imediatamente pós-guerra posicionou-se em algum lugar entre dois polos: modernização e marxismo. A modernização tinha como centro uma questão enganosamente simples: quando ocorre rápida expansão econômica, o que mais acontece e por quê? (A questão é enganosa porque o "o que mais" podia ser causa, efeito ou estar meramente correlacionado com a expansão econômica; tanto o 
"o que mais" quanto a expansão econômica também podiam resultar de alguma outra transformação profunda.) As ideias de modernização diziam respeito às consequências de mudanças sociais em grande escala, definidas variadamente como industrialização, urbanização ou disseminação de novas formas culturais. Elas comumente apoiavam-se na premissa de que a industrialização acabaria produzindo uma convergência mundial sobre algo semelhante à estrutura social europeia ocidental ou norte-americana. A história social inspirada na teoria da modernização concentrava-se em como pessoas comuns experimentavam essas grandes mudanças sociais, reagiam a elas ou mesmo causavam-nas.

O marxismo, em contraste, centrava suas investigações em causas, consequências e fenômenos concomitantes do capitalismo. Durante os anos do pós-guerra, a existência visível de grandes potências socialistas fortaleceu a premissa marxista de que o capitalismo era apenas uma das várias rotas históricas possíveis, e não necessariamente o estágio histórico final. As ideias do marxismo diziam respeito ao desenvolvimento de instituições capitalistas, transformações da experiência de vida pela mudança econômica e condições para a libertação da população trabalhadora. A história social inspirada no marxismo concentrou-se na transição do feudalismo para o capitalismo, no crescimento da indústria de capital concentrado e nas consequências dessas duas mudanças para a ação coletiva popular. Teoria da modernização e marxismo coincidiam em tratar a política pública como uma arena fortemente afetada por processos não políticos e em insistir na importância de investigar como o grosso da população experimentava as grandes mudanças sociais. Na medida em que visivelmente revigoravam abordagens antiquárias e reformistas mais antigas da história social, esses pesquisadores do período do pós-guerra influenciaram fortemente a escrita da história em geral.

Na década de 1990, os termos de discordância e acordo haviam se alterado fundamentalmente. Embora alguns marxistas e teóricos da modernização consumados tenham sobrevivido, em geral as escolhas dominantes dos historiadores sociais anglo-americanos passaram a variar do reducionismo cultural ou discursivo a variedades concorrentes de realismo. No extremo cultural-discursivo, alguns historiadores sociais trataram o empreendimento basicamente como uma luta retórica à qual nenhum padrão externo de validade podia ser aplicado: nessa visão, interpretações persuasivas da experiência social passada serviam a fins políticos contemporâneos, inclusive a ilustração geral relativa à condição humana. No extremo realista, prevaleceu a segmentação: especialistas em história econômica, demografia histórica, 
história urbana, história da agricultura, história da família, cultura material e política popular extraíam, todos, alguma inspiração da história social anterior, mas executavam suas investigações em substancial isolamento uns dos outros. Todavia, partilhavam um pressuposto geral de que a estrutura social existe, é conhecível e presta-se à reconstrução histórica sistemática. Entre as duas perspectivas, sintetizadores e alguns poucos historiadores gerais tenazes buscavam levar a sério questóes da cultura e do discurso ao mesmo tempo em que continuavam a procurar modos válidos de estabelecer como pessoas comuns experimentam mudanças sociais de grande escala.

O declínio da teoria da modernização e do marxismo implicou mudanças em método, argumento e apresentação. $\mathrm{O}$ esquadrinhamento de registros organizacionais, a biografia coletiva e até a história dos vencidos perderam parte de seu brilho para os historiadores sociais. Críticos atacaram a divisão das pessoas em categorias de classe e a atribuição de propriedades coletivas a essas categorias como reificação injustificada. Muitos historiadores sociais começaram a rejeitar o que cada vez mais consideravam explicações reducionistas - em especial, mas não exclusivamente, aquelas baseadas em categorias de classe - em favor de interpretaçôes com foco em motivos, crenças e experiências. E também começaram a abandonar o estilo "documente e explique" da história social em favor da narrativa. Um marco decisivo ocorreu com o chamado de Lawrence Stone, em 1979, para um retorno à narrativa. A intervenção de Stone teve peso ainda maior porque ele havia sido um dos grandes defensores e praticantes da biografia coletiva (ou, como ele a chamava, prosopografia). Em vez da sociologia analítica, a etnografia interpretativa tornou-se o modelo preferido por muitos historiadores sociais.

Esse resumo esquemático minimiza a centralidade do marxismo popular - como estilo analítico e objeto de crítica - na história social anglo-americana. Ele corre, apropriadamente, como um fio vermelho ao longo de todo o período de 1945 a 2000. No ressurgimento da história social no pós-guerra, marxistas britânicos como Eric Hobsbawm e George Rudé foram pioneiros no estudo das multidões, do ativismo político local e das consequências do desenvolvimento capitalista, chegando a inspirar muitos estudiosos da América do Norte (cf. Hobsbawm, 1964; Rudé, 1964). Pouco tempo depois, Hobsbawm começou uma série de sínteses magistrais, período por período, da história britânica e ocidental, organizada em torno de perspectivas marxistas e centrada na história social; sínteses que continuou a produzir até a década de 1990 (por exemplo, Hobsbawm, 1975, 1994). 
Durante a década de 1960, Barrington Moore Jr. (uma espécie de materialista histórico, mas com certeza não um marxista estrito) e E. P. Thompson (um vigoroso participante do marxismo britânico) tornaram a formação e a transformação de classes ainda mais centrais para a história social do que tinham sido antes. Origens sociais da ditadura e da democracia (1966), de Moore, comparava as histórias política e social de Inglaterra, França, Estados Unidos, China, Japão e Índia (com referências comparativas frequentes a Alemanha e Rússia), em uma investigação das bases de classe de várias formas de política nacional no século XX. A obra forneceu um modelo para comparações de longas trajetórias políticas nacionais que encorajou alguns historiadores sociais a empreender suas próprias grandes comparaçôes, e outros a contestar, modificar ou aplicar a abordagem de Moore em seus próprios trabalhos sobre tempos e lugares particulares.

Dentro da história social autodefinida como tal, $A$ construção da classe trabalhadora na Inglaterra (1963), de Thompson, teve um impacto fora do comum. Thompson integrou uma gama extraordinária de evidências literárias, políticas e culturais com descrições gráficas de luta popular ao analisar transformaçôes da consciência da classe operária inglesa entre 1780 e 1832. Polemista brilhante, ele atacou tanto o reducionismo materialista de parte de seus colegas marxistas quanto o desdém pela política popular de parte de historiadores não marxistas e antimarxistas. E também levou adiante a ideia de classe não como um atributo fixo de pessoas situadas em certas posiçôes partilhadas nas hierarquias sociais ou na organização da produção, mas como uma relação dinâmica, negociada continuamente entre trabalhadores e seus exploradores.

O estilo metodológico e a linha de argumentação de Thompson moldaram uma geração inteira de historiadores sociais na Grã-Bretanha e em toda parte. Uma ampla gama de investigadores buscou aplicar a análise de Thompson a outros lugares, executar estudos mais detalhados dentro de seus pressupostos gerais ou contestar algum aspecto de seu argumento. A "formação" das classes trabalhadoras ou o fracasso dela tornaram-se temas padrão de história social.

As classes sociais constituíram um importante princípio organizador para a pesquisa em história social em todo o período de 1945 a 2000. Cinco posiçôes bastante diferentes competiam, no entanto, entre si:

1. A classe social consiste na posição, individual ou coletiva, em uma hierarquia de prestígio, riqueza e/ou poder, ou é um caso especial dessa diferenciação hierárquica. 
2. A classe social descreve uma vinculação, individual ou coletiva, a mercados, o que produz diferenças importantes na qualidade de vida.

3. A classe social reside na consciência mútua e/ou na cultura compartilhada entre conjuntos de pessoas que coletivamente consideram-se (não importa se com ou sem razão) superiores ou inferiores a outras pessoas.

4. A classe social é a, ou depende da, localização coletiva dentro de um sistema de produção.

5. A classe social é uma ilusão, ou, na melhor das hipóteses, uma descrição equivocada de desigualdades que seriam mais bem caracterizadas de outras maneiras, por exemplo, como competência individual, cultura étnica ou especialização ocupacional variáveis.

Os historiadores sociais muitas vezes combinavam duas dessas posições, argumentando, por exemplo, que a posição em uma hierarquia (1) gera consciência mútua ou cultura partilhada (3), ou que as hierarquias existem (1), mas sua cristalização em classes sociais opostas nunca ou raramente ocorre (5). Os marxistas ofereceram a síntese mais ambiciosa dessas posições, argumentando, por exemplo, que a localização em um sistema de produção (4) determina a posição hierárquica (1), a vinculação a mercados (2) e a cultura partilhada (3). Não obstante, muitas das disputas mais mordazes da história social opõem defensores de uma posição a defensores de outra.

Na sequência do trabalho de Thompson, por exemplo, abriu-se uma divisão significativa entre os estudiosos de classe que seguiram a ênfase discursiva de seus textos e aqueles que adotaram o igualmente thompsoniano estudo da classe como uma relação fundada na organização da produção. Muitos analistas da linguagem e da cultura começaram a argumentar que a classe só existia na medida em que as pessoas falavam em termos de classe, concebiam-se nesses termos e formavam uma cultura distintiva baseada em classe. Seguia-se que na história europeia e norte-americana, onde a linguagem de classe explícita era difícil de ser encontrada, a classe raramente ou nunca ocorrera. Seus oponentes relacionais contrapunham que a classe existe na luta, onde quer que as partes ocupem posições antagônicas na organização da produção, e, consequentemente, que a classe era uma característica duradoura da história euro-americana. Embora alguns pesquisadores de história (por exemplo, Steinberg, 1999) tenham preenchido parcialmente a lacuna ao integrar o estudo do discurso e da cultura em análises de redes e lutas sociais, o debate continua. 
Nem todos os historiadores sociais anglo-americanos, é certo, organizaram suas investigações - positiva ou negativamente - em torno de ideias de classe. Três grandes alternativas disputavam a atenção: (1) a mudança das mentalidades, como objeto de estudo ou como causa de alteraçōes na vida social; (2) outras divisões categoriais, notadamente por gênero, raça e etnia; e (3) mudança em importantes instituiçōes e estruturas, incluindo as consequências dessas mudanças. A primeira alternativa fomentou uma colaboração maior com historiadores intelectuais e antropólogos culturais. Assim, estudos de consumo, cultura material e participação cívica (a despeito de suas possíveis vinculações com investigações de cientistas sociais sobre os mesmos fenômenos) comumente enfatizavam mudanças nas mentalidades, e muitas vezes recorriam a modelos antropológicos.

A segunda alternativa reproduzia a ambivalência da história social como um todo, já que dividia os praticantes entre aqueles que enfatizavam continuidades com estudos de ciências sociais contemporâneos sobre desigualdades categoriais e aqueles que optavam pela interpretação cultural. Assim, a história das mulheres abarcava desde a análise demográfica e as abordagens econômicas até as análises de discurso. A terceira alternativa empurrava os historiadores sociais para a especialização em algum tipo de instituição, e portanto para a colaboração com cientistas sociais que estavam examinando instituiçôes aparentemente similares no presente. Desse modo, história urbana, história demográfica, história da família e história econômica atraíram, todas, alguns historiadores sociais para um engajamento especializado em campos adjacentes das ciências sociais.

Para os historiadores sociais da primeira vertente, as mentalidades jogam um papel similar àquele da cultura em antropologia; elas figuram como causas gerais cujas origens e dinâmicas raramente são examinadas em minúcias (cf. Kuper, 1999). Na história britânica, por exemplo, ideias de cultura popular, cultura do consumidor e cultura política servem com frequência como explicaçôes para o comportamento ou a ação política de pessoas comuns. As explicações de John Brewer para a política de rua teatral que girava em torno de John Wilkes durante a década de 1760 (por exemplo, Brewer, 1980) exemplificam o melhor trabalho nessa linha. Brewer não usa a palavra "mentalidades", mas declara que uma explicação apropriada da política do século XVIII

[...] terá de ser, antes de mais nada, tanto instrumental quanto dinâmica. Ela deve, em outras palavras, propor-se a mostrar como, por que e com que propósitos 
em mente uma visão ou argumento particular foi apresentado ou expressado. Mudanças ou desenvolvimentos no argumento podem ser explicados como uma espécie de processo de resolução de problemas à luz de um conjunto de normas e convençôes, bem como em face de novas dificuldades ou mudanças de perspectiva (Brewer, 1976, p. 34).

Brewer aplica explicitamente esse argumento à política popular e às maquinações dos líderes políticos. "A legitimação e a expressão de crença política", ele argumenta, "não têm de assumir a forma de palavra impressa ou mesmo falada. A conduta ritualizada, o emprego de símbolos ou o engajamento em ação simbólica podem ser usados para transmitir um credo político" (Idem, p. 22). Dado que os idiomas culturais disponíveis moldam a maneira como as pessoas lidam umas com as outras, um observador perspicaz de ideias e convenções prevalecentes como Brewer pode fornecer um novo insight sobre os significados de eventos específicos. Mas a dificuldade surge quando o mesmo historiador recua para analisar mudanças ou interações de longo prazo entre mentalidades e instituições. Então o status causal das mentalidades torna-se decisivo.

A dificuldade é evitável. Como muitos linguistas e historiadores da ciência, alguns historiadores sociais (por exemplo, Zelizer, 1994) reconhecem que a cultura não é uma força autônoma por trás da vida social, mas um elemento constitutivo das relações sociais. Entendimentos partilhados e sua representação em símbolos, objetos e práticas (uma definição razoável de cultura) limitam a interação social, mas também alteram-se como consequência da interação social. Até agora, porém, a investigação dessa interação dinâmica entre cultura e relações sociais não se tornou um programa central para historiadores sociais.

Estudos de outras divisões categoriais que não a classe seguiram tipicamente apenas um tipo de divisão, com mais frequência de gênero, etnia, raça, religião ou preferência sexual. Com exceção do trabalho sobre migração e política urbana, na verdade, os historiadores sociais nessa linha comumente adotaram apenas uma categoria por vez: a história das mulheres e não a história das relaçôes entre mulheres e homens, a história dos negros e não a história das divisões raciais, e assim por diante. Como resultado, os historiadores sociais anglo-americanos estabeleceram especialidades em análises de uma única categoria, cada uma delas chamando atenção para o caráter distintivo da categoria, repreendendo a história geral por sua negligência e representação errônea dessa categoria, e adotando, por mais indiretamente que seja, 
temas políticos correntes que envolviam a categoria. Muitos desses exames de divisões categoriais aliam-se estreitamente com o amplo programa intelectual chamado estudos culturais: interpretações históricas, literárias e políticas de experiências culturais aparentemente distintivas. Não obstante, veteranos da análise de classes que mudaram para outras categorias (por exemplo, Louise Tilly et al., 1997) têm papel importante nessa linha de pensamento; eles frequentemente concebem gênero, raça, religião, etnia ou preferência sexual em termos de relações entre categorias adjacentes ou concorrentes.

\section{História social e ciência social}

Estudar mudanças de instituições e estruturas é juntar forças, ao menos implicitamente, com ciências sociais adjacentes. Mas o grau de colaboração autoconsciente com cientistas sociais varia de forma significativa segundo as instituiçōes e as estruturas sob escrutínio. Historiadores sociais que lidam com mudança populacional, por exemplo, quase sempre adquirem familiaridade com ideias e métodos demográficos. Estudos de instituições religiosas, em contraste, com frequência procedem com pouca ou nenhuma referência a análises sociológicas, antropológicas ou políticas contemporâneas da religião. Aqui as sequências historiográficas importam. Onde cientistas sociais iniciaram ativamente o estudo histórico de alguma instituição ou estrutura pouco examinada pelos próprios historiadores, com frequência atraíram seguidores entre estes. No caso da história demográfica, por exemplo, demógrafos que queriam explicar mudanças recentes em fertilidade, mortalidade e nupcialidade adaptaram seus métodos a populações históricas como meio de tratar períodos longos em lugares bem documentados. Então a demografia histórica acabou produzindo grandes dividendos também para historiadores sociais (cf. Gillis, Tilly e Levine, 1992; Hanagan, 1989; Levine, 1984, 1987; Charles Tilly, 1978; Wrigley e Schofield, 1981).

Onde os historiadores sociais há muito tempo já vinham considerando um tópico em seus próprios termos, eles aceitaram contribuiçôes das ciências sociais com muito mais relutância. Assim, estudos históricos de cultura popular já há muito estabelecidos valeram-se pouco de desenvolvimentos logicamente paralelos em antropologia, linguística e sociologia. Análises de historiadores sociais de política popular, prática religiosa, sexualidade e vida associativa mostraram-se igualmente resistentes a contribuições das ciências sociais. A grande exceção tem sido a abertura de muitos historiadores sociais a algo que eles chamavam de antropologia. Num exame mais atento, porém, 
fica claro que essa antropologia não envolve práticas antropológicas rotineiras como etnografia, arqueologia, análise linguística formal, reconstrução de sistemas de parentesco ou inspeção de cultura material, mas significa interpretação compreensiva de práticas, símbolos e representações sociais no estilo de Clifford Geertz.

A atividade chamada de ciência social histórica [social science history] (cf. Monkkonen, 1994) estabeleceu os laços mais fortes entre história e disciplinas sociais adjacentes. Para esse lago fluíram correntes de demografia, economia, sociologia, geografia, linguística e antropologia, cada uma produzindo um conjunto parcialmente separado de redemoinhos. Aqui as fronteiras entre história e outras disciplinas ficaram borradas, na medida em que especialidades como história demográfica, história antropométrica (estudos de bem-estar pela mudança e variação em altura e peso), história da migração e história da mobilidade social constituíram comunidades acadêmicas parcialmente autônomas. Nesses campos especiais, as agendas de pesquisa muitas vezes refletiam prioridades dentro das ciências sociais tão relevantes quanto aquelas na história nacional sob exame. Estudos de mobilidade social, por exemplo, contribuíram para a documentação da história do Canadá ou dos Estados Unidos, mas frequentemente se organizaram em torno de um par de questóes distintivo: primeiro, em que medida a industrialização produz mudanças gerais no ritmo e na direção do movimento de uma posição a outra? Segundo, instituições e culturas nacionais têm um impacto significativo sobre o ritmo e a direção do movimento de uma posição a outra? Nenhuma dessas questôes predomina na historiografia canadense ou americana como um todo.

Ainda assim, o estudo da mobilidade social americana ilustra como a história social às vezes influencia a escrita da história geral. Por algum tempo depois da Segunda Guerra Mundial, uma porção de sociólogos americanos examinou a mobilidade ocupacional (comparando filhos com pais ou seguindo as carreiras ocupacionais de indivíduos) por meio da compilação de dossiês sobre indivíduos a partir de catálogos de cidades. Esse trabalho, orientado por questões de sociólogos sobre mobilidade e industrialização, atraiu pouca atenção de historiadores. Mas, em 1964, Stephan Thernstrom publicou um livro sobre Newburyport, Massachusetts, no século XIX, que utilizava análises similares de catálogos de cidades para fins muito diferentes. A escolha de Newburyport foi um lance de gênio, já que o antropólogo W. Lloyd Warner havia conduzido uma série de estudos influentes nessa cidade, rebatizada de Yankee City para a publicação (cf. Warner et al., 1963). 
Warner havia reconstruído a história de Newburyport no século XIX a partir de recordações escritas e orais de moradores, concluindo que uma estrutura de oportunidades muito aberta havia se fechado durante a industrialização do século XIX. A posição de Warner coincidia com a de muitos historiadores gerais nos Estados Unidos e articulava-se com uma das questões dominantes na historiografia norte-americana: os Estados Unidos foram e são a terra das oportunidades?

A análise de Thernstrom revelou uma mobilidade interclasses relativamente baixa durante o século XIX, contrariando a ideia de declínio da mobilidade, e identificou modos significativamente diferentes de mobilidade (por exemplo, via investimento em imóveis ou em educação) para diferentes categorias étnicas. Thernstrom prosseguiu com um estudo ainda mais ambicioso de Boston, Massachusetts, que confirmou a maioria das conclusões da pesquisa de Newburyport (cf. Thernstrom, 1973). No interior das histórias sociais, dezenas de jovens acadêmicos logo passaram a emular Thernstrom, realizando estudos paralelos de outras cidades e categorias étnicas em suas teses de doutorado. Eles também estenderam a biografia coletiva à análise de respostas manuscritas ao censo, registros do ciclo vital e outras fontes. Ao mesmo tempo, historiadores gerais dos Estados Unidos sentiram-se compelidos a modificar suas afirmações sobre o lugar da mobilidade social e seu declínio na vida estadudinense como um todo.

Com o tempo, sem dúvida, a popularidade dos estudos de mobilidade de cidades individuais, conjuntos de cidades e categorias étnicas sofreu um declínio significativo. Dentro do campo especializado, os pesquisadores encontraram limites técnicos à sua capacidade de rastrear geograficamente populações, mulheres e categorias étnicas móveis. Depois do choque inicial dos resultados de Thernstrom, nunca mais se encontrou uma maneira eficaz de transmitir o significado dos achados dos estudos de mobilidade a grandes audiências de historiadores. Os editores cansaram-se de livros que detalhavam as histórias de mobilidade de grupos étnicos em cidades americanas específicas. A mudança geral dos historiadores sociais da análise categorial em estilo sociológico para a narrativa interpretativa como etnografia retrospectiva reduziu o apelo da análise de mobilidade para a disciplina como um todo. Os estudos urbanos de desigualdade e mobilidade de forma alguma desapareceram, mas passaram a constituir um subcampo especializado aliado à geografia, à sociologia e à ciência política.

No entanto, a proeminência temporária dos estudos de mobilidade traz lições para a história social em geral. Primeiro, quando os historiadores 
sociais conseguem estabelecer ligações efetivas entre uma nova fonte ou método e uma das grandes questões que já estão na agenda histórica geral, eles influenciam a escrita da história como um todo. Segundo, quando essa ligação de fonte ou de método com perguntas significativas identifica novos projetos viáveis para indivíduos isolados, as teses de doutorado tornam-se ponto decisivo para a difusão de uma nova variedade de história social. Terceiro, projetos bem-sucedidos em história social tendem a atrair o interesse geral por algum tempo, depois a cristalizar-se em subcampos especializados aliados a disciplinas adjacentes. Por fim, e mais importante: apesar da criação de métodos, vocabulários, associaçōes, periódicos e carreiras especializados, a história social anglo-americana continua a participar dos grandes debates que agitam os historiadores como um todo.

Para onde tudo isso conduzirá os historiadores sociais? Qualquer previsão nesse domínio mistura extrapolação a partir do passado com wishful thinking. Consideremos apenas três cenários possíveis: mais do mesmo, polarização aguçada e dialética. Mais do mesmo daria continuidade às tendências documentadas anteriormente: especialização cada vez maior, crescente alinhamento de premissas epistemológicas com escolha de tema, absorção continuada de algumas especialidades em disciplinas das ciências sociais adjacentes e, portanto, declínio do diálogo no interior da história social como um todo. Mais do mesmo acabaria por destruir a história social como campo coerente. Dado que alguns analistas (por exemplo, Joyce, 1995) já estão anunciando, e até comemorando, esse destino, os praticantes de hoje devem levá-lo a sério.

A polarização aguçada também poderia ocorrer, com a divisão fundamental separando mais as posições epistemológicas e ontológicas do que os fenômenos sob exame. De um lado, podemos ver uma reunião daqueles que consideram que a matéria da vida social são mentes, crenças, consciência ou linguagem, e, portanto, é fundamentalmente indeterminada ou pelo menos inacessível à explicação sistemática. Esses historiadores sociais alinhariam-se com a história intelectual, a história cultural e certas versões de antropologia. Por outro lado, poderíamos ter uma variedade de realistas que afirmam que a vida social surge sistematicamente de escolhas individuais ou transações interpessoais, e permanece disponível para observação e explicação. Nessas circunstâncias, o diálogo poderia prosseguir vigorosamente em cada um dos lados da fronteira, mas seria bastante improvável que ocorresse, e muito menos que tivesse sucesso, entre os dois campos.

A interação dialética também poderia desenvolver-se, com descendentes do velho materialismo servindo como tese, o reducionismo linguístico e 
cultural como antítese, e uma história social renovada como síntese. Isso poderia acontecer se os descendentes do materialismo levassem a cultura, a linguagem e a construção social a sério, tentando não só integrá-las em análises de processos sociais, mas também tratá-las como objetos de explicação sistemática: como e por que a cultura, a linguagem e a construção social variam e mudam? Isso também poderia acontecer se os estudiosos da cultura, da linguagem e da construção social realizassem exames de como esses fenômenos interagem com relações sociais concretas. Melhor ainda, materialistas e culturalistas poderiam ambos trabalhar na direção dos fundamentos uns dos outros, não necessariamente concordando, mas ao menos chegando a alguns padrões comuns de explicação. $\mathrm{O}$ reexame da linguagem como uma produção social, de diferenças categoriais por gênero, classe, raça ou outros princípios como instituições geradas socialmente, da luta coletiva como construção e reconstrução social define problemas dignos da atenção dos historiadores sociais, e começa a preencher a lacuna aparente entre eventos e ideias. Como diz Robert Descimon, a inclinação empírica dos historiadores sociais vai levá-los muito além das controvérsias atuais que opõem a história social à história dos eventos.

\section{Referências Bibliográficas}

Аввотт, Andrew. (1994), "History and sociology: the lost synthesis". In: MonkKonen, Eric (org.). Engaging the past: the uses of history across the social sciences. Durham, NC, Duke University Press.

(1998), "The causal devolution". Sociological Methods and Research, 27: 148-181.

BELCHEM, John. (1990), Industrialization and the working class: the english experience, 1750-1900. Aldershot, UK, Scolar Press.

BREWER, John. (1976), Party ideology and popular politics at the accession of George III. Cambridge, Cambridge University Press.

. (1980), "The Wilkites and the law, 1763-74: a study of radical notions of governance”. In: BREWER, John \& STYLES, John (orgs.). An ungovernable people: the english and their law in the Seventeenth and Eighteenth Centuries. New Brunswick, NJ, Rutgers University Press.

CalHoun, Craig. (1982), The question of class struggle: social foundations of popular radicalism during the Industrial Revolution. Chicago, University of Chicago Press.

CLARK, Anna. (1995), The struggle for the Breeches: gender and the making of the British working class. Berkeley, University of California Press. 
Clark, Samuel. (1995), State and status: the rise of the State and aristocratic power in Western Europe. Montreal, McGill-Queen's University Press.

CoHen, Lizabeth. (1990), Making a New Deal: industrial workers in Chicago, 19191939. Cambridge, Cambridge University Press.

Descimon, Robert. (1999), "Autopsie du massacre de l'Hôtel de Ville (4 juillet 1652): Paris et la 'Fronde des Princes”. Annales. Histoire, Sciences Sociales, 54: 319-352.

Frader, Laura L. \& Rose, Sonya O. (orgs.). (1996), Gender and class in modern Europe. Ithaca, NY, Cornell University Press.

Geertz, Clifford. (1980), Negara: the theatre State in Nineteenth-Century Bali. Princeton, NJ, Princeton University Press.

Geremer, Bronislaw. (1994), Poverty: a history. Oxford, Blackwell.

Gillis, John R., Tilly, Louise A. \& Levine, David (orgs.). (1992), The European experience of declining fertility: a Quiet Revolution 1850-1970. Oxford, Blackwell.

Hammond, J. L. \& Hammond, Barbara. (1917), The town labourer, 1760-1832. Londres, Longmans.

Hanagan, Michael P. (1989), Nascent proletarians: class formation in post-revolutionary France. Oxford, Basil Blackwell.

Новsвашм, E. J. (1964), Labouring men. Londres, Weidenfeld. . (1975), The age of capital, 1848-1875. Londres, Weidenfeld and Nicolson. . (1994), The age of extremes: a history of the world, 1914-1991. Nova York, Pantheon.

JOYCE, Patrick. (1991), Visions of the people: industrial England and the question of class, 1848-1914. Cambridge, Cambridge University Press. (1995), "The end of social history?". Social History, 20: 73-92.

KuPER, Adam. (1999), Culture: the anthropologists' account. Cambridge, MA, Harvard University Press.

Levine, David (org.). (1984), Proletarianization and family history. Orlando, FL, Academic Press. . (1987), Reproducing families. Cambridge, Cambridge University Press.

MonKKonen, Eric H. (org.). (1994), Engaging the past: the uses of history across the social sciences. Durham, NC, Duke University Press.

Moore, Barrington Jr. (1966), Social origins of dictatorship and democracy. Boston, Beacon.

Novick, Peter. (1988), That noble dream: the "objectivity question" and the American historical Profession. Cambridge, Cambridge University Press.

OlzAK, Susan. (1989), "Analysis of events in the study of collective action". Annual Review of Sociology, 15: 119-141.

Rucht, Dieter, Koopmans, Ruud \& Neidhardt, Friedhelm (orgs.). (1998), Acts of dissent: new developments in the study of protest. Berlim, Sigma Rainer Bohn Verlag. 
RudÉ, George. (1964), The crowd in history. Nova York, Wiley.

Stedman Jones, Gareth. (1983), Languages of class: studies in English working class history, 1832-1982. Cambridge, Cambridge University Press.

STEINBERG, Marc W. (1999), Fighting words: working-class formation, collective action, and discourse in early Nineteenth-Century England. Ithaca, NY, Cornell University Press.

STONE, Lawrence. (1979), "The revival of narrative: reflections on a New Old History". Past and Present, 86: 3-24.

Thernstrom, Stephan. (1964), Poverty and progress. Cambridge, MA, Harvard University Press.

(1973), The other Bostonians: poverty and progress in the American metropolis.

Cambridge, MA, Harvard University Press.

Thompson, E. P. (1963), The making of the English working class. Londres, Gollancz.

TilLY, Charles (org.). (1978), Historical studies of changing fertility. Princeton, NJ, Princeton University Press. (1998), Roads from past to future. Lanham, MD, Rowman \& Littlefield.

Tiluy, Louise A. \& Gurin, Patricia. (1990), Women, politics and change. Nova York, Russell Sage Foundation.

TilLy, Louise A. et al. (1997), "Scholarly controversy: women, work, and citizenship". International Labor and Working-Class History, 52: 1-71.

Vernon, James. (1993), Politics and the people: a study in English political culture c. 1815-1867. Cambridge, Cambridge University Press.

Warner, W. Lloyd et al. (1963), Yankee city. New Haven, Ct, Yale University Press. Willigan, J. Dennis \& LYNCH, Katherine A. (1982), Sources and methods of historical demography. Nova York, Academic Press.

Wrigley, E.A. \& SCHOfield, R. S. (1981), The population history of England, 1541 1871: a reconstruction. Cambridge, MA, Harvard University Press.

Zelizer, Viviana. (1994), The social meaning of money. Nova York, Basic Books.

ZunZ, Olivier (org.). (1985), Reliving the past: the worlds of social history. Chapel Hill, University of North Carolina Press. 


\section{Resumo}

A história social anglo-americana desde 1945

$\mathrm{O}$ artigo examina temas, métodos e tendências analíticas dominantes na análise da história social e da ciência social produzidas na Inglaterra e nos Estados Unidos a partir da Segunda Guerra Mundial, apontando a proeminência no debate de duas grandes vertentes, o marxismo e a teoria da modernização. $\mathrm{O}$ autor reflete sobre achados e limites de ambas as correntes.

Palavras-chave: História social; Teoria da modernização; Marxismo.

\section{Abstract}

Anglo-American social history since 1945

This article examines the mainstream themes, methods and analytical trends in social history and social science from Britain and the United States since the Second World War. It highlights the predominance of two main theories in the debate: Marxism and modernization theory. The author evaluates the main findings and limits of both theories.

Keywords: Social history; Modernization theory; Marxism.

Texto recebido em 1/8/2012 e aprovado em 6/8/2012. 